ORIGINAL ARTICLE

\title{
A participatory approach to the study of lifting demands and musculoskeletal symptoms among Hong Kong workers
}

\author{
S Yeung, A Genaidy, J Deddens, C Shoaf, P C Leung
}

Occup Environ Med 2003;60:730-738

See end of article for authors' affiliations ......................

Correspondence to: Associate Professor S S Yeung, Department of Rehabilitation Sciences, The Hong Kong Polytechnic University, Hung Hom, Hong Kong; simon.yeung@polyu. edu.hk

Accepted

17 December 2002

\begin{abstract}
Aims: To investigate the use of a worker based methodology to assess the physical stresses of lifting tasks on effort expended, and to associate this loading with musculoskeletal outcomes (MO).

Methods: A cross sectional study was conducted on 217 male manual handling workers from the Hong Kong area. The effects of four lifting variables (weight of load, horizontal distance, twisting angle, and vertical travel distance) on effort were examined using a linguistic approach (that is, characterising variables in descriptors such as "heavy" for weight of load). The numerical interpretations of linguistic descriptors were established. In addition, the associations between on the job effort and $M O$ were investigated for 10 body regions including the spine, and both upper and lower extremities.

Results: $M O$ were prevalent in multiple body regions (range 12-58\%); effort was significantly associated with $M O$ in 8 of 10 body regions (odds ratios with age adjusted ranged from 1.31 for low back to 1.71 for elbows and forearm). The lifting task variables had significant effects on effort, with the weight of load having twice the effect of other variables; each linguistic descriptor was better described by a range of numerical values rather than a single numerical value.

Conclusions: The participatory worker based approach on musculoskeletal outcomes is a promising methodology. Further testing of this approach is recommended.
\end{abstract}

ower back pain (LBP) is a complex disorder that is influenced by numerous factors in the workplace. This -complexity arises because many physical and nonphysical work factors simultaneously impact multiple biological functions in the human body. This in turn may create biological dysfunction leading to LBP. About 97\% of occupationally related LBP are labelled "non-specific" because of this complexity. ${ }^{1}$ To date, medical practitioners rely on the patient's symptoms of "aches, pains, and discomfort" in order to diagnose the occupational problem at hand. Therefore, until the biologically complex relation between work factors and LBP is fully understood, it is logical to rely on the self reports made by workers to determine the extent of physical loading on the spine leading to LBP.

Manual lifting is an activity commonly performed in the workplace that is closely linked to LBP. It has been shown in a number of investigations that objective measures of physical loading are significantly associated with musculoskeletal outcomes in the lower back region..$^{2-5}$ Manual handling work may also result in musculoskeletal symptoms in other body regions. Leboeuf-Yde and colleagues ${ }^{6}$ reported combined lower back and neck problems in the general population. In the working population, Holmstrom and colleagues $^{7}$ found combined lower back, hip, and knee problems among construction workers. Since the documentation of musculoskeletal symptoms in the workplace depends on self reports made by workers, it is essential to utilise workers in the evaluation of work related factors and in the formulation of intervention strategies for the purpose of controlling the incidence of musculoskeletal symptoms. While self reported evaluations are commonly used in assessing the exposure of risk factors at the workplaces, ${ }^{8-20}$ to our knowledge, a worker based methodology has not been fully developed in assessing the physical stresses of the lifting task variables and to associate this loading with musculoskeletal outcomes. This approach is participatory in that it requires worker feedback as input and therefore enables the worker (that is, patient) to play an active role in the health assessment process. Such a methodology would be extremely valuable to the medical practitioner in order to diagnose and treat LBP. This does not necessarily mean that the medical practitioner has to rely solely on worker based reports. However, such information would be an important element in an array of data to assess LBP until new biological indicators are found. This is the subject of the research reported in this paper.

The objectives of this study were to examine the relation between effort and lifting task parameters and to model musculoskeletal symptoms in different body regions as a function of the effort expended during the performance of industrial manual lifting tasks. The model adopted in this study is depicted in fig 1 and consists of two parts. In the first part, effort was a function of four lifting task parameters: weight of load, horizontal distance, twisting angle (or angle of asymmetry), and vertical travel distance. These four lifting task parameters were defined according to the NIOSH lifting equation and are recognised as important factors for the assessment of infrequent lifting activities. ${ }^{21}$ In this study, both effort and lifting task factors were defined in linguistic descriptors. For example, weight of load was quantified in terms of three linguistic levels: "light", "moderate", and "heavy". Thus, each worker was presented with lifting conditions (as a function of four lifting variables) in linguistic terms. The worker was then asked to evaluate the effort associated with the lifting condition in linguistic terms. In addition, the linguistic-numerical mapping of each lifting task factor was established. For example, the worker was asked to determine the range in $\mathrm{kg}$ which he was $100 \%$ certain belonged to a "light" load. In the second part, the worker was asked, in a cross sectional design, to determine on the job effort level and the corresponding musculoskeletal symptoms in 10 body parts. As such, the musculoskeletal

Abbreviations: LBP, low back pain; MO, musculoskeletal outcomes 
Main messages

- Musculoskeletal symptoms were prevalent in multiple body regions among experienced manual material handlers.

- Effort was significantly associated with musculoskeletal symptoms in 8 of 10 body parts.

- Workers rated different level of perceived effort on different lifting task variables.

- Weight of load had twice the effect of other lifting task parameters on effort; there were minor differences among other lifting task variables in terms of their effects on effort.

- A range of numerical values represented one linguistic descriptor rather than a single numerical value.

symptoms are linked to the level of effort expended and can be traced back to the lifting conditions, possibly resulting in the reported level of on the job effort.

This study was conducted on a group of experienced manual handling workers in the Hong Kong area. The reliability and validity of the linguistic and linguisticnumerical approaches and its application in the field study have been established by Yeung and colleagues. ${ }^{22-25}$

\section{METHODS}

\section{Study design and population}

A worker participatory approach was adopted in this cross sectional study. Two hundred and seventeen male workers (mean (SD) age 38.76 (11.53) years), from three major industries-warehouse operations, delivery services, and manufacturing-volunteered to participate in this study. All participants were experienced manual handling workers with 8.65 (10.21) years of experience in manual lifting.

\section{Data collection procedures}

A structured interview, which followed a set of standardised questionnaires, was conducted at the workers' respective companies by the same investigator. Data collection procedures consisted of two parts. The first part was the evaluation of the effects of lifting task parameters on perceived physical effort, and assessment of the numerical meaning of the linguistic descriptors used to describe the lifting task parameters. The second part dealt with the lifting task demands at work and work outcomes. Data collection was

\section{Policy implications}

- The participatory worker based approach in assessing the physical stresses of the lifting tasks warrants further investigation.

- Future research should be directed to develop musculoskeletal outcome profiles for different body regions in order to fully evaluate the effects of lifting task demands.

conducted at the workers' workplace at a time convenient to both the management and the workers. The entire data collection procedures took about 90 minutes to complete for each worker.

\section{Assessment of lifting task parameters effects on physical effort (part 1 of model in fig 1)}

The interactive effects of five lifting variables on the amount of physical effort exerted were evaluated by a structured interview, with a set of standardised questionnaires to the workers. The lifting variables were operationally defined as those described in the revised NIOSH lifting equation, ${ }^{21}$ and quantified with three levels of linguistic descriptor: (1) weight of load (light, moderate, heavy); (2) horizontal distance (close, moderate, far); (3) twisting angle (small, moderate, large); (4) vertical travel distance (short, moderate, long); and (5) vertical height location at origin of lift (floor or waist level). These conditions were presented to the worker in a standardised format. Workers were asked to assess the level of each effort using one of the following levels: "very low", "low", "moderate", "somewhat high", "high", "very high", and "extremely high".

\section{Assessment of the numerical meaning of the linguistic descriptors}

To map the numerical meaning of each linguistic descriptor (for example, "light", "moderate", "heavy") used by the workers in characterising lifting task parameters, they were asked to determine the physical meaning of each linguistic descriptor by marking on a scale a range of which he is $100 \%$ certain that it corresponds to the specific level of the linguistic descriptor. They were instructed that each lifting task parameter might consist of more linguistic descriptors than those assigned in the study. For example, the weight of load can be quantified using any of the following descriptors: "extremely light", "very, very light", "very light", "light",

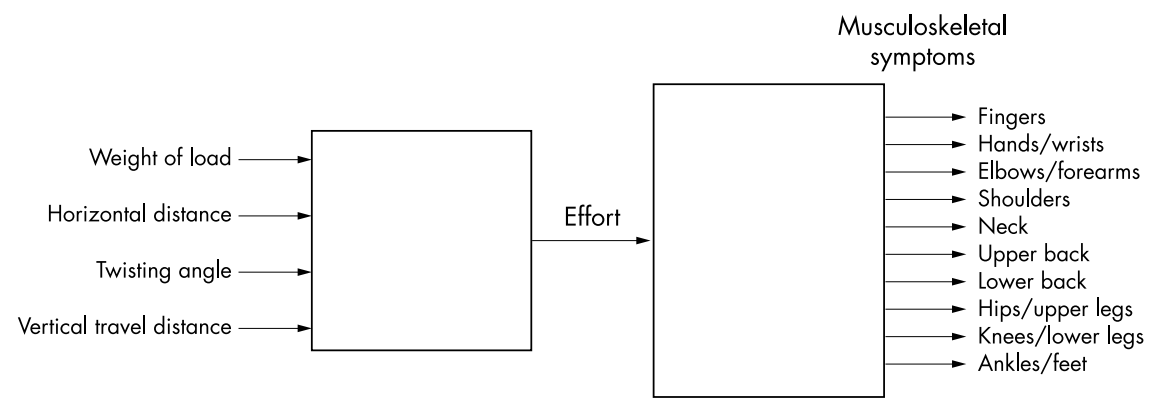

Effort $=f$ (weight of load, horizontal distance, twisting angle, vertical travel distance)

Musculoskeletal symptoms $=f($ effort level)

Figure 1 Model adopted in the study. 
"moderate", "heavy", "very heavy", "very, very heavy", and "extremely heavy". However, they were required only to assess the weight of load in terms of the three middle descriptors-that is, "light", "moderate", and "heavy".

\section{Exposure classification and assessment of work outcomes (part 2 of model in fig 1)}

Workers' exposure to the lifting tasks demand at work was evaluated. Similar to the determination of the physical effort associated with the lifting task parameters, the workers were asked to use one of the following descriptors: "very low", "low", "moderate", "somewhat high", "high", "very high", and "extremely high" that best described the perceived effort at work.

Musculoskeletal outcomes were used as the outcome measure for the lifting tasks exposure. The Nordic Musculoskeletal Symptom Survey ${ }^{26}$ was used to document the presence or absence of any "aches, pains, or discomforts" in 10 body regions within the past 12 months. The 10 body regions are: lower back, upper back, hips/upper legs, knees/ lower legs, ankles/feet, neck, shoulders, elbows/forearms, wrists/hands, and fingers.

\section{Statistical analysis}

To achieve the objectives of this study, the data collected were subjected to a number of statistical analyses. The relation between lifting task parameters and effort were first examined using PROC MIXED of the Statistical Analysis Software. ${ }^{27}$ This procedure is particularly suited for the repeated design employed in this study and the possible correlation among the different observations. Based on the results of the main effect model, a new variable was created to categorise the 81 lifting conditions into 11 groups. The main effect model revealed that the effect of the two height locations on the evaluation of effort is practically no different, and from the point estimate, weight of load has almost twice the effect on effort as that of horizontal distance, twisting angle, and vertical travel distance. The point estimates of horizontal distance, twisting angle, and vertical travel distance are nearly the same. Thus, the new variable was created with similar loading to horizontal distance, twisting angle, vertical distance, and loading of 2 to weight of load.

Frequency distributions were also developed describing the linguistic-numerical mapping for each lifting task parameter. The frequency distributions were calculated in two steps. First, the proportions of participants reporting a certain numerical value of a lifting task parameter were calculated for the three linguistic descriptors. For example, $10 \mathrm{~kg}$ was reported as "light" by $28 \%$ of the participants, "moderate" by $35 \%$ of the subjects, and "heavy" by $0 \%$ of the subject population. Second, the proportions obtained for different
Table 1 Main effect model for effort as a function of lifting task parameters

\begin{tabular}{|c|c|c|c|c|}
\hline Effect & $\begin{array}{l}\text { Point } \\
\text { estimate }\end{array}$ & $\begin{array}{l}\text { Standard } \\
\text { error }\end{array}$ & $\begin{array}{l}\text { Degrees of } \\
\text { freedom }\end{array}$ & $p$ value \\
\hline Intercept & -1.980 & 0.071 & 216 & $<0.0001$ \\
\hline $\begin{array}{l}\text { Weight of } \\
\text { load }\end{array}$ & 0.999 & 0.008 & 17E3 & $<0.0001$ \\
\hline $\begin{array}{l}\text { Horizontal } \\
\text { distance }\end{array}$ & 0.572 & 0.008 & 17E3 & $<0.0001$ \\
\hline $\begin{array}{l}\text { Twisting } \\
\text { angle }\end{array}$ & 0.610 & 0.008 & 17E3 & $<0.0001$ \\
\hline $\begin{array}{l}\text { Vertical travel } \\
\text { distance }\end{array}$ & 0.512 & 0.008 & 17E3 & $<0.0001$ \\
\hline
\end{tabular}

values within the numerical range of each task parameter were graphed for the three linguistic descriptors.

The relation between effort and musculoskeletal symptoms was investigated for 10 body regions using the PROC LOGISTIC procedure of the Statistical Analysis Software. The musculoskeletal symptoms were modelled as a binary variable ( 0 for absence of symptoms and 1 for absence of symptoms). Possible confounders of age, education level, and perceived fitness levels on perceived effort were tested with these variables as covariates and adjusted accordingly. Hosmer and Lemeshow lack of fit tests were used to test for goodness of fit of the models.

\section{RESULTS}

Table 1 shows the main effect model used to classify the 81 lifting conditions into the 11 groups. The possible lifting conditions that belong to each of this group are summarised in the appendix. The number of lifting conditions belonging to each group ranged from 1 to 14; five groups had clusters of more than 10 lifting conditions in each group. Table 2 shows the frequency distribution on each linguistic levels of effort for the 11 lifting groups. Thus, it is possible to examine the effort distribution for each group and to determine the effort value with some level of certainty ranging from 0.0 to 1.0.

The following observations can be made about the linguistic-numerical mapping:

- The distribution for the middle and upper descriptors (for example, "moderate", "heavy", "far") are almost normally distributed with skewness less than 1 (table 3). However, the lower descriptors (for example, "low", "short") are in general skewed, with skewness ranging from 1.12 to 1.98 (table 3 ). Thus, the numerical range of "low" levels of descriptors was smaller than that for the

Table 2 Effort frequency distribution for different groups

\begin{tabular}{|c|c|c|c|c|c|c|c|c|c|}
\hline \multirow[b]{2}{*}{ Group no. } & \multirow[b]{2}{*}{ No. lifting conditions } & \multirow[b]{2}{*}{ Observation no. } & \multicolumn{7}{|l|}{ Effort } \\
\hline & & & 1 & 2 & 3 & 4 & 5 & 6 & 7 \\
\hline 1 & 1 & 1 & 0.90 & 0.09 & 0.01 & 0.00 & 0.00 & 0.00 & 0.00 \\
\hline 2 & 3 & $2-4$ & 0.65 & 0.28 & 0.06 & 0.01 & 0.00 & 0.00 & 0.00 \\
\hline 3 & 7 & $5-11$ & 0.40 & 0.38 & 0.17 & 0.03 & 0.01 & 0.00 & 0.00 \\
\hline 4 & 10 & $12-21$ & 0.24 & 0.38 & 0.26 & 0.09 & 0.02 & 0.01 & 0.00 \\
\hline 5 & 12 & $22-33$ & 0.13 & 0.30 & 0.30 & 0.18 & 0.06 & 0.02 & 0.01 \\
\hline 6 & 14 & $34-47$ & 0.05 & 0.23 & 0.30 & 0.23 & 0.13 & 0.04 & 0.01 \\
\hline 7 & 13 & $48-60$ & 0.02 & 0.14 & 0.24 & 0.25 & 0.21 & 0.10 & 0.04 \\
\hline 8 & 10 & $61-70$ & 0.01 & 0.08 & 0.19 & 0.22 & 0.24 & 0.18 & 0.08 \\
\hline 9 & 7 & $71-77$ & 0.00 & 0.05 & 0.11 & 0.18 & 0.24 & 0.22 & 0.19 \\
\hline 10 & 3 & $78-80$ & 0.00 & 0.02 & 0.08 & 0.12 & 0.15 & 0.29 & 0.33 \\
\hline 11 & 1 & 81 & 0.00 & 0.01 & 0.05 & 0.06 & 0.13 & 0.17 & 0.59 \\
\hline
\end{tabular}




\begin{tabular}{|c|c|c|c|c|c|c|c|}
\hline Variable & Level & Median & Mean & Standard deviation & Min & Max & Skewness \\
\hline \multirow[t]{3}{*}{ Weight of load (kg) } & Light & 5.0 & 5.1 & 1.43 & 2.6 & 12.5 & 1.53 \\
\hline & Moderate & 12.5 & 12.6 & 2.54 & 5.5 & 20.0 & -0.03 \\
\hline & Heavy & 21.0 & 20.8 & 3.06 & 12.0 & 35.0 & 0.35 \\
\hline \multirow[t]{3}{*}{ Horizontal distance $(\mathrm{cm})$} & Close & 30.0 & 30.4 & 3.0 & 25.5 & 47.5 & 1.12 \\
\hline & Moderate & 44.0 & 44.0 & 6.4 & 30.0 & 62.5 & -0.17 \\
\hline & Far & 60.0 & 59.0 & 8.3 & 36.5 & 72.5 & -0.51 \\
\hline \multirow{3}{*}{ Twisting angle (degrees) } & Small & 19.5 & 18.9 & 4.6 & 5.0 & 40.5 & 1.49 \\
\hline & Moderate & 41.5 & 41.7 & 10.3 & 13.5 & 67.0 & 0.22 \\
\hline & Large & 70.0 & 67.0 & 14.6 & 17.5 & 132.5 & -0.47 \\
\hline \multirow{3}{*}{$\begin{array}{l}\text { Vertical travel distance } \\
(\mathrm{cm})\end{array}$} & Short & 40.0 & 41.5 & 9.5 & 25.0 & 98.5 & 1.98 \\
\hline & Moderate & 79.0 & 81.5 & 19.1 & 45.3 & 156.3 & 0.48 \\
\hline & Long & 133.1 & 126.4 & 25.9 & 50.0 & 190.0 & -0.09 \\
\hline
\end{tabular}

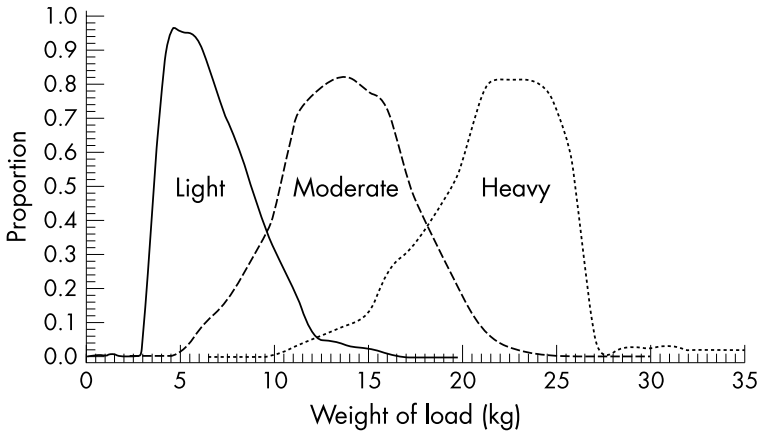

Figure 2 Linguistic-numerical $(\mathrm{kg})$ mapping for weight of load.

"moderate" and "high" levels of linguistic descriptors (figs 2-5).

- The peak of each distribution decreased in value with an increase in the level of the linguistic descriptor. The highest proportion values attained for the low linguistic descriptors were no more than 0.96 (figs 2-5).

- A given numerical value for a lifting task parameter translates to different linguistic interpretations with a given certainty factor (frequency of occurrence). For example, a $20 \mathrm{~kg}$ load is viewed by $55 \%$ of the participants as "heavy", by $14 \%$ as "moderate", and by $0 \%$ as "light". On the other hand, a $4 \mathrm{~kg}$ load is considered as "light" by $90 \%$ of the workers; none of the workers determined that the $4 \mathrm{~kg}$ load is either "moderate" or "heavy" (fig 2).

Table 4 shows that the prevalence rates of musculoskeletal symptoms were in excess of $20 \%$ for nine of the ten body

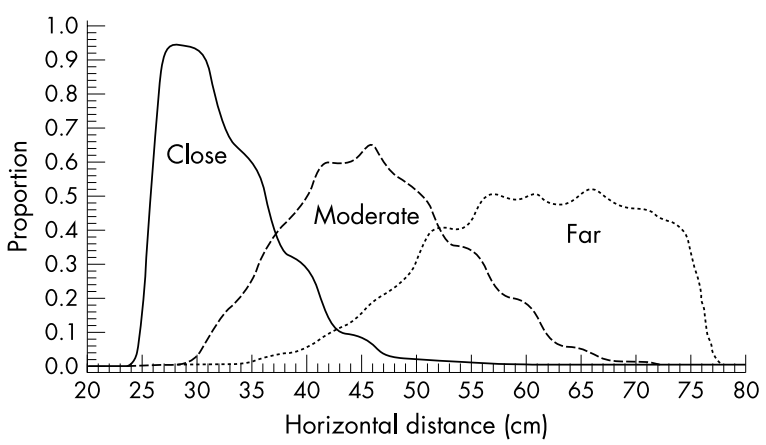

Figure 3 Linguistic-numerical $(\mathrm{cm})$ mapping for horizontal distance.

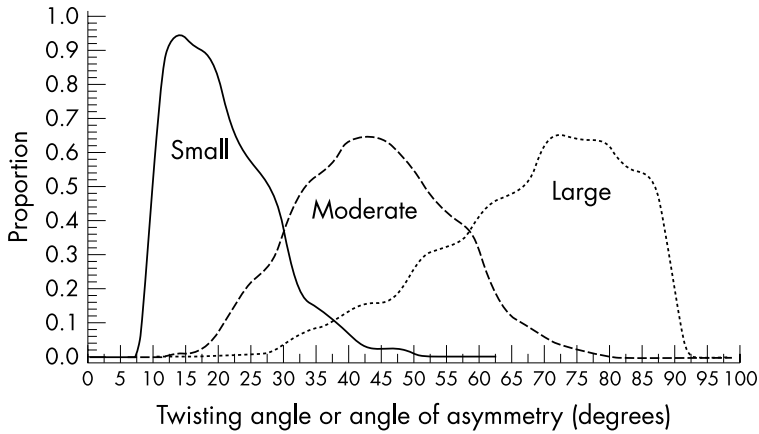

Figure 4 Linguistic-numerical (degrees) mapping for twisting angle.

regions examined. The prevalence rate of finger symptoms was at $12 \%$. These values show that the musculoskeletal symptoms are not only prevalent in the lower back region, but also in other body regions such as the shoulders, neck, and upper back which showed prevalence rates in excess of $30 \%$.

Significant associations were obtained between effort and musculoskeletal symptoms in eight body regions (table 5). The statistical associations were not significant for the hips/ upper legs and knees/lower legs. The significant odds ratios (age adjusted) ranged between 1.31 (for the lower back) and 1.71 (for elbows and forearms). Other worker demographics and behavioural data, including perceived physical fitness level, education level, and work experience did not influence the musculoskeletal outcomes after adjustment for age. Hosmer and Lemeshow lack of fit tests revealed goodness of fit in these models $(\mathrm{p}=0.30-0.89)$. When the perceived physical effort at work is "very low", the respective

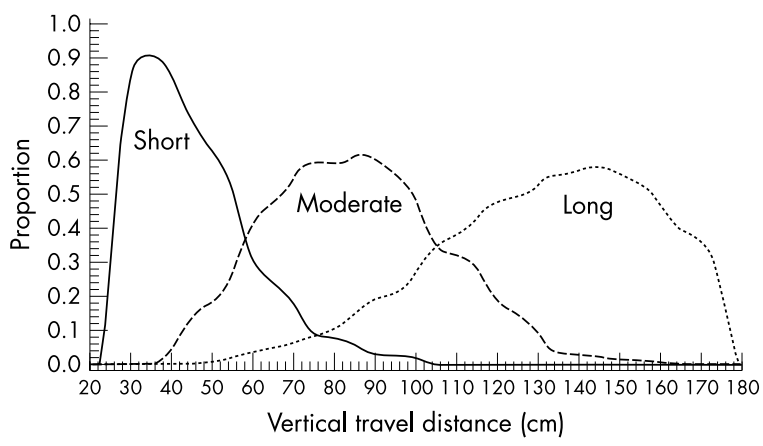

Figure 5 Linguistic-numerical $(\mathrm{cm})$ mapping for vertical travel distance. 
Table 4 Overall prevalence rates of musculoskeletal symptoms for different body parts

\begin{tabular}{ll}
\hline Body part & Overall prevalence (\%) \\
\hline Upper body & 33 \\
Lower back & 58 \\
Neck & 31 \\
Shoulders & 39 \\
Elbows/forearms & 21 \\
Hands/wrists & 21 \\
Fingers & 12 \\
Hips/upper legs & 32 \\
Knees/lower legs & 21 \\
Ankles/feet & 27 \\
\hline
\end{tabular}

prevalence rates for the 10 body regions are: lower back, $67 \%$; neck, 33\%; shoulder, 33\%; hands and wrists, 13\%; and nil for other body regions. Table 6 summarises the odds ratios of the musculoskeletal symptoms at the eight body regions for the 11 lifting groups compared to "very low" effort.

\section{DISCUSSION}

Direct measurements, systematic observations, and self reported evaluation are the three main strategies used in assessing the exposure of risk factors at the workplace. ${ }^{28-30}$ Since lifting has been identified as the main risk factor for LBP, evaluation has been focused on the direct measurement of the exposure of risks in different lifting conditions. Many of these investigations reported significant associations between the physical demands of manual lifting activities and musculoskeletal outcomes in the lower back region. ${ }^{2-5}$ However, these studies emphasised musculoskeletal outcomes in the lower back region. Very little, however, is known about musculoskeletal outcomes in other body regions. Such information would be helpful to the medical practitioner in order to understand the full impact of lifting task variables on multiple body parts. Although these studies advanced our knowledge in this respective area, none of these investigations made use of participatory approaches, which include worker based methodologies. In particular, the Lifting Index of the NIOSH Lifting Equation relied on the expertise of its committee members in the absence of data available in the scientific literature. ${ }^{21}$ Worker expertise in the assessment of the physical demands of lifting activities can be considered analogous to the expertise that NIOSH employed in its establishment of the Lifting Equation. Medical practitioners are largely dependent on the patient's (that is, worker's) reports of musculoskeletal symptoms to make their diagnosis.

This study was conducted in order to investigate a worker based methodology in the assessment of lifting task demands in addition to the evaluation of musculoskeletal outcomes in multiple body regions. Workers' self reported evaluation is the most common approach in epidemiological studies. ${ }^{29}{ }^{30}$ Among these, a checklist is commonly used in the evaluation of the stressfulness of lifting jobs at the workplace. ${ }^{13-20}$ In the design of the checklist based approach, researchers either use descriptive values ${ }^{13-17}$ (for example, high and low), or numerical $\operatorname{scores}^{18-20}$ (for example, $10-15 \mathrm{~kg}$ ) to each item, but not both. The linguistic approach in this study is novel in that it takes into account both the linguistic and numerical representation of the lifting task parameters.

The prevalence rates of musculoskeletal symptoms reported in this study clearly suggest that workers are experiencing aches, pains, and discomfort in not only the lower back area, but also in multiple body parts. In particular, the prevalence rates in the upper back, neck, shoulders, hips/ upper legs, and ankles/feet ranged between $27 \%$ and 39\%.
Table 5 Logistic regression analyses for musculoskeletal symptoms as a function of effort for different body parts

\begin{tabular}{lcl}
\hline Body part & p value & Adjusted OR $(95 \% \mathrm{Cl})$ \\
\hline Upper back & $<0.001$ & $1.625(1.28$ to 2.06$)$ \\
Lower back & 0.021 & $1.31(1.04$ to 1.64$)$ \\
Neck & 0.004 & $1.42(1.12$ to 1.80$)$ \\
Shoulders & $<0.001$ & $1.48(1.18$ to 1.86$)$ \\
Elbows/forearms & $<0.0001$ & $1.71(1.31$ to 2.22$)$ \\
Hands/wrists & 0.004 & $1.47(1.13$ to 1.91$)$ \\
Fingers & 0.002 & $1.65(1.20$ to 2.27$)$ \\
Hips/upper legs & 0.806 & $0.97(0.78$ to 1.22$)$ \\
Knees/lower legs & 0.869 & $1.02(0.79$ to 1.32$)$ \\
Ankles/feet & 0.001 & $1.49(1.16$ to 1.89$)$ \\
\hline OR, odds ratio; Cl, confidence interval.
\end{tabular}

Further analyses indicate that every two to three reports of lower back cases were accompanied with at least one case of aches/pains/discomfort in the aforementioned body parts. Moreover, the significant associations between on the job effort and musculoskeletal outcomes in eight body parts revealed increased odds of musculoskeletal symptoms with increase perceived level of effort at work. Thus, it is recommended in future studies to develop musculoskeletal outcome profiles for different body regions in order to fully evaluate the effects of lifting task demands. It has to be noted that prevalence rate of lower back symptoms is high (67\%), even when the on the job effort evaluated by the workers is "very low". This possibly indicates that workers with lower levels of physical fitness or history of back injury had already been placed on work tasks with lower physical demands. Nonetheless, the high prevalence rate even at "very low" physical demand task clearly suggests that lower back symptoms are common in work life, and besides physical factors, other variables such as psychosocial factors ${ }^{31} 32$ may mediate the proliferation of lower back symptoms.

The findings of this worker based methodology support earlier research on the role of lifting task parameters in effort exertion. The four lifting variables examined in this study (defined according to those in the NIOSH Lifting Equation) were significantly associated with effort. In particular, the results recognise the relative importance of weight of load in comparison to other task parameters. This is consistent with the published literature (for example, NIOSH used weight of load in the numerator of the Lifting Index). Our study suggests that the workers considered effect of weight of load on perceived effort is almost twice the effect of other parameters. There are only minor differences among the effects of horizontal distance, twisting angle, and vertical travel distance on perceived effort rated by the workers. This is somewhat in disagreement with the guidelines instituted in the discounting of lifting task multipliers. ${ }^{33}$ For example, the maximum discounting of horizontal distance multiplier was clearly much more significant than that of twisting angle multiplier. This disagreement may be attributed to, among other things, the different criteria utilised in the derivation of these multipliers. However, the study findings are in agreement with our pilot studies on both expert workers and professionals. ${ }^{22} 3435$

In this study, the effects of 81 lifting conditions on the effort expended by 217 workers were classified into 11 distinct groups. When lifting variables were assigned the highest levels of linguistic descriptors, this single lifting condition stood out as the most demanding physical requirement. The next group consisted of "heavy" weights and two "high" linguistic descriptors of two other variables, with the last variable assuming "moderate" levels. The third group from the top consisted of: (1) three "high" levels (including weight) and "low" on the fourth variable; (2) two 


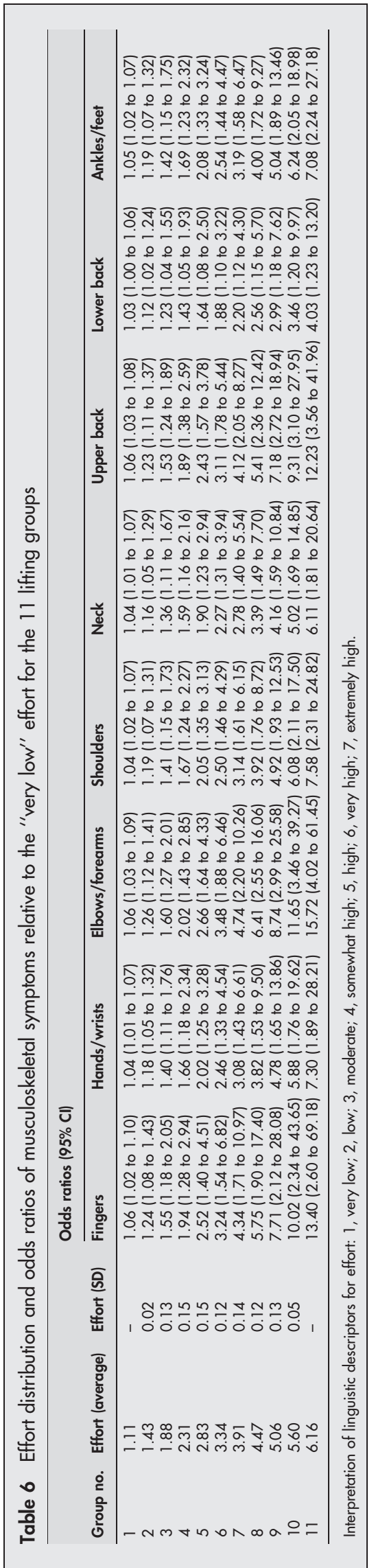

"high" levels (including weight of load) and two "moderate" levels; and (3) "high" levels for horizontal distance/twisting angle/vertical travel distance and "moderate" weight level. The aforementioned discussion clearly shows the influential role of weight of load in the effort expended during manual lifting tasks.

The physical interpretation of the linguistic descriptor is a strategy used to map the physical meaning of the linguistic descriptors used by the workers. Thus, the linguistic variable has a wider context and application. Figures $2-5$ provide the numerical interpretations of linguistic descriptors employed in this study. A number of observations can be made from these graphs. A linguistic descriptor is not mapped into a single numerical value. It is better described as a range of numerical values with varied degrees of proportion distribution as shown in these figures. Furthermore, a given numerical value might not necessary belong to only one linguistic descriptor. The degree of certainty of that numerical value which belongs to a particular linguistic descriptor is a function of the frequency distribution. Around or close to the limits of numerical ranges, the worker population sampled in this study is more certain about the meaning of "low" and "high" linguistic descriptors. However, in between the limits, each numerical value may belong to each of the three linguistic descriptors with a degree of certainty bounded between 0.0 and 1.0. This characteristic of human interpretation of linguistic descriptors might probably explain why the reliability and validity of worker based evaluation provided mix results in the literature. For instance, Pope and colleagues $^{18}$ found that workers had great difficulties in estimating the frequency of manual activities in absolute value. However, when a four point ordinal scale was used to document the frequency of manual activities at work, the degree of agreement between self reported and observed frequency was satisfied $(r=0.70)$. Recently, Halpern and colleagues $^{16}$ further suggested the use of non-linear or asymmetric scales in risk factor questionnaire design to capture workers' sensory threshold and perceived exertion.

The results of this study strongly suggest that further investigation of the worker based methodology is warranted. This methodology could be applied in the workplace or as a form of a practical health assessment instrument for the medical practitioner. The participatory worker based methodology is data driven as the input variables for analysis are described by the worker. The database developed by this worker based assessment might serve both as the linguistic and numerical guidelines for the evaluation of manual lifting task at the workplace. The frequency distribution database is usually friendly and can be easily applied by the managers and supervisors at the workplace. For instance, in determining the weight of load that the workers can handle at the workplace, the supervisors can refer to the database to determine the percentile of accommodation for a specific weight of load.

When the worker's health is assessed in a medical setting, the data collected relative to work activities and musculoskeletal symptoms could be input to a "Smart" software program. The software could then apply the methodology and output the results to the medical practitioner. The medical practitioner could use the output from the "Smart" software to facilitate the diagnosis and treatment of $\mathrm{MO}$ in manual handling workers. For short term assessment, the software serves to identify which lifting task parameters should be modified to alleviate symptoms of any given MO the worker is currently experiencing. For example, consider the case of a manual handling worker experiencing LBP after changing jobs. He is not sure if the symptoms are due to a medical history of mild LBP or his new work activities. Although he does not feel he is expending significantly more effort in this 
job relative to his last one, he is experiencing moderate LBP. The worker's new task parameters may be input to the Smart software program to evaluate whether his current work conditions put him at a high risk of injury. With the information output, the medical practitioner can then advise the worker on how to modify the task parameters to alleviate his symptoms. Conversely, the software can also rule out the current lifting task conditions as the source of the problem.

The Smart software program results can also be used to guide long term care of MO. The results could identify body regions at future risk and thus guide the medical practitioner in preventative efforts. For example, in the case of the worker discussed previously, the software may identify him as being at risk for symptoms in other body parts if his current work conditions continue unchanged. With this knowledge, the medical practitioner could advise the worker of the possible $\mathrm{MO}$, recommend action to prevent them, and then monitor the health of these other body parts in future visits.

As the worker can best describe the work system and the medical practitioner can best diagnose and prescribe treatment, the participatory worker based approach allows the two participants to become partners in the health care process, with the Smart software acting as the bridge between their respective areas of expertise. As such, the worker based methodology applied through the Smart software empowers both the worker and the medical practitioner. While the Smart program facilitates interaction between the clinicians and workers, workers' privacy and confidentiality have to be noted. Effort and care has to be taken to ensure the confidentiality of the workers' record in this Smart software. The data should only be entered by authorised personnel, and stringent security procedures should be in place to prevent unauthorised access of the program.

It has to be noted that the present investigation was based on male workers. Application of the database to female workers needs to be exercised with caution. A cross sectional design was used to investigate the association between perceived effort and musculoskeletal symptoms. Thus, causality cannot be established from these findings. Further research should be focused on testing this methodology on musculoskeletal outcomes in a prospective design on the same group of workers, and also on female workers.

\section{ACKNOWLEDGEMENTS}

The work described in this paper was partially supported by a grant from the Hong Kong Occupational Safety and Health Council (research grant no. 98001). Special thanks are extended to $\mathrm{Mr}$ Wong Man Hung for his assistance in the data collection.

\section{Authors' affiliations}

S Yeung, Department of Rehabilitation Sciences, The Hong Kong

Polytechnic University, Hong Kong

A Genaidy, C Shoaf, Industrial \& Manufacturing Engineering Program, University of Cincinnati, Cincinnati, OH 45221-0072, USA

J Deddens, Department of Mathematical Sciences, University of Cincinnati, Cincinnati, OH 45221, USA

P C Leung, Department of Orthopaedic and Traumatology, The Chinese University of Hong Kong, Hong Kong

\section{APPENDIX}

Table Al shows average effort as a function of lifting task parameters.

\begin{tabular}{|c|c|c|c|c|c|c|}
\hline $\begin{array}{l}\text { Observation } \\
\text { no. }\end{array}$ & $\begin{array}{l}\text { Weight } \\
\text { of load }\end{array}$ & $\begin{array}{l}\text { Horizontal } \\
\text { distance }\end{array}$ & $\begin{array}{l}\text { Twisting } \\
\text { angle }\end{array}$ & $\begin{array}{l}\text { Vertical } \\
\text { travel distance }\end{array}$ & $\begin{array}{l}\text { Average } \\
\text { effort }\end{array}$ & Sum \\
\hline 1 & 1 & 1 & 1 & 1 & 1.11 & 5 \\
\hline 2 & 1 & 1 & 1 & 2 & 1.41 & 6 \\
\hline 3 & 1 & 1 & 2 & 1 & 1.43 & 6 \\
\hline 4 & 1 & 2 & 1 & 1 & 1.46 & 6 \\
\hline 5 & 1 & 2 & 1 & 2 & 1.73 & 7 \\
\hline 6 & 2 & 1 & 1 & 1 & 1.77 & 7 \\
\hline 7 & 1 & 1 & 2 & 2 & 1.80 & 7 \\
\hline 8 & 1 & 2 & 2 & 1 & 1.83 & 7 \\
\hline 9 & 1 & 1 & 1 & 3 & 1.94 & 7 \\
\hline 10 & 1 & 3 & 1 & 1 & 1.96 & 7 \\
\hline 11 & 1 & 1 & 3 & 1 & 2.10 & 7 \\
\hline 12 & 2 & 1 & 1 & 2 & 2.14 & 8 \\
\hline 13 & 2 & 2 & 1 & 1 & 2.15 & 8 \\
\hline 14 & 1 & 2 & 2 & 2 & 2.17 & 8 \\
\hline 15 & 2 & 1 & 2 & 1 & 2.19 & 8 \\
\hline 16 & 1 & 3 & 1 & 2 & 2.29 & 8 \\
\hline 17 & 1 & 2 & 1 & 3 & 2.31 & 8 \\
\hline 18 & 1 & 1 & 2 & 3 & 2.39 & 8 \\
\hline 19 & 1 & 1 & 3 & 2 & 2.42 & 8 \\
\hline 20 & 1 & 3 & 2 & 1 & 2.51 & 8 \\
\hline 21 & 1 & 2 & 3 & 1 & 2.57 & 8 \\
\hline 22 & 2 & 2 & 1 & 2 & 2.64 & 9 \\
\hline 23 & 2 & 1 & 2 & 2 & 2.67 & 9 \\
\hline 24 & 3 & 1 & 1 & 1 & 2.73 & 9 \\
\hline 25 & 2 & 2 & 2 & 1 & 2.74 & 9 \\
\hline 26 & 2 & 1 & 1 & 3 & 2.77 & 9 \\
\hline 27 & 2 & 3 & 1 & 1 & 2.79 & 9 \\
\hline 28 & 1 & 3 & 2 & 2 & 2.82 & 9 \\
\hline 29 & 1 & 2 & 2 & 3 & 2.84 & 9 \\
\hline 30 & 2 & 1 & 3 & 1 & 2.87 & 9 \\
\hline 31 & 1 & 3 & 1 & 3 & 2.88 & 9 \\
\hline 32 & 1 & 2 & 3 & 2 & 2.88 & 9 \\
\hline 33 & 1 & 1 & 3 & 3 & 3.02 & 9 \\
\hline 34 & 3 & 1 & 1 & 2 & 3.16 & 10 \\
\hline 35 & 1 & 3 & 3 & 1 & 3.19 & 9 \\
\hline 36 & 2 & 2 & 2 & 2 & 3.21 & 10 \\
\hline 37 & 3 & 2 & 1 & 1 & 3.23 & 10 \\
\hline 38 & 3 & 1 & 2 & 1 & 3.25 & 10 \\
\hline
\end{tabular}




\begin{tabular}{|c|c|c|c|c|c|c|}
\hline $\begin{array}{l}\text { Observation } \\
\text { no. }\end{array}$ & $\begin{array}{l}\text { Weight } \\
\text { of load }\end{array}$ & $\begin{array}{l}\text { Horizontal } \\
\text { distance }\end{array}$ & $\begin{array}{l}\text { Twisting } \\
\text { angle }\end{array}$ & $\begin{array}{l}\text { Vertical } \\
\text { travel distance }\end{array}$ & $\begin{array}{l}\text { Average } \\
\text { effort }\end{array}$ & Sum \\
\hline 39 & 2 & 2 & 1 & 3 & 3.27 & 10 \\
\hline 40 & 2 & 3 & 1 & 2 & 3.29 & 10 \\
\hline 41 & 2 & 1 & 3 & 2 & 3.30 & 10 \\
\hline 42 & 2 & 1 & 2 & 3 & 3.36 & 10 \\
\hline 43 & 2 & 3 & 2 & 1 & 3.39 & 10 \\
\hline 44 & 2 & 2 & 3 & 1 & 3.41 & 10 \\
\hline 45 & 1 & 3 & 2 & 3 & 3.47 & 10 \\
\hline 46 & 1 & 3 & 3 & 2 & 3.51 & 10 \\
\hline 47 & 1 & 2 & 3 & 3 & 3.52 & 10 \\
\hline 48 & 3 & 2 & 1 & 2 & 3.69 & 11 \\
\hline 49 & 3 & 1 & 2 & 2 & 3.72 & 11 \\
\hline 50 & 3 & 1 & 1 & 3 & 3.75 & 11 \\
\hline 51 & 3 & 2 & 2 & 1 & 3.85 & 11 \\
\hline 52 & 2 & 3 & 1 & 3 & 3.90 & 11 \\
\hline 53 & 2 & 3 & 2 & 2 & 3.90 & 11 \\
\hline 54 & 2 & 2 & 2 & 3 & 3.91 & 11 \\
\hline 55 & 2 & 2 & 3 & 2 & 3.92 & 11 \\
\hline 56 & 3 & 3 & 1 & 1 & 3.96 & 11 \\
\hline 57 & 2 & 1 & 3 & 3 & 4.03 & 11 \\
\hline 58 & 3 & 1 & 3 & 1 & 4.03 & 11 \\
\hline 59 & 2 & 3 & 3 & 1 & 4.09 & 11 \\
\hline 60 & 1 & 3 & 3 & 3 & 4.13 & 11 \\
\hline 61 & 3 & 2 & 2 & 2 & 4.28 & 12 \\
\hline 62 & 3 & 2 & 1 & 3 & 4.33 & 12 \\
\hline 63 & 3 & 1 & 2 & 3 & 4.35 & 12 \\
\hline 64 & 3 & 3 & 1 & 2 & 4.42 & 12 \\
\hline 65 & 3 & 1 & 3 & 2 & 4.45 & 12 \\
\hline 66 & 2 & 3 & 2 & 3 & 4.53 & 12 \\
\hline 67 & 2 & 2 & 3 & 3 & 4.58 & 12 \\
\hline 68 & 2 & 3 & 3 & 2 & 4.60 & 12 \\
\hline 69 & 3 & 3 & 2 & 1 & 4.61 & 12 \\
\hline 70 & 3 & 2 & 3 & 1 & 4.61 & 12 \\
\hline 71 & 3 & 2 & 2 & 3 & 4.94 & 13 \\
\hline 72 & 3 & 3 & 2 & 2 & 5.00 & 13 \\
\hline 73 & 3 & 2 & 3 & 2 & 5.01 & 13 \\
\hline 74 & 3 & 1 & 3 & 3 & 5.02 & 13 \\
\hline 75 & 3 & 3 & 1 & 3 & 5.02 & 13 \\
\hline 76 & 2 & 3 & 3 & 3 & 5.18 & 13 \\
\hline 77 & 3 & 3 & 3 & 1 & 5.24 & 13 \\
\hline 78 & 3 & 2 & 3 & 3 & 5.54 & 14 \\
\hline 79 & 3 & 3 & 2 & 3 & 5.60 & 14 \\
\hline 80 & 3 & 3 & 3 & 2 & 5.65 & 14 \\
\hline 81 & 3 & 3 & 3 & 3 & 6.16 & 15 \\
\hline \multicolumn{7}{|c|}{$\begin{array}{l}\text { Interpretation of linguistic descriptors for task parameters: } 1 \text {, light, close, small, or short; } 2 \text {, moderate; } 3 \text {, heavy } \\
\text { far, large, or long. } \\
\text { Interpretation of linguistic descriptors for effort: 1, very low; } 2 \text {, low; } 3 \text {, moderate; } 4 \text {, somewhat high; } 5 \text {, high; } 6 \\
\text { very high; } 7 \text {, extremely high. } \\
\text { The data have been ordered by increasing value of effort. } \\
\text { Sum }=2 \times \text { weight level + horizontal distance level + twisting angle level + vertical travel distance level. }\end{array}$} \\
\hline
\end{tabular}

\section{REFERENCES}

1 Frank JW, Kerr MS, Brooker AS, et al. Disability resulting from occupational low back pain, part l: what do we know about primary prevention? A review of the scientific evidence on prevention before disability begins. Spine 1995.21:2908-17.

2 Chaffin DB, Park KS. A longitudinal study of low-back pain as associated with occupational weight lifting factors. Am Ind Hyg Assoc J 1974:34:513-25.

3 Ayoub MM, Selan JL, Liles DH. An ergonomics approach for the design of manual materials-handling tasks. Human Factors 1983:25:507-15.

4 Marras WS, Lavender SA, Leurgans SE, et al. The role of dynamic threedimensional trunk motion in occupationally-related low back disorders. The effects of workplace factors, trunk position and trunk motion characteristic on risk of injury. Spine 1993;18:617-28.

5 Waters TR, Baron SL, Piacitelli LA, et al. Evaluation of the revised NIOSH liffing equation. A cross-sectional epidemiologic study. Spine 1999;24:386-95.

6 Leboeuf-Yde C, Lauritsen JM, Lauritzen, T. Why has the search for causes of low back pain largely been nonconclusive? Spine 1997;22:877-81.

7 Holmström EB, Lindell J, Moritz U. Low back and neck/shoulder pain in construction workers: occupational workload and psychosocial risk factors. Spine 1992;17:663-71.

8 Ando S, Ono Y, Shimaoka M, et al. Associations of self estimated workloads with musculoskeletal symptoms among hospital nurses. Occup Environ Med 2000;57:211-16.

9 Devereux JJ, Vlachonikolis IG, Buckle PW. Epidemiological study to investigate potential interaction between physical and psychosocial factors at work that may increase of risk of symptoms of musculoskeletal disorder of the neck and upper limb. Occup Environ Med 2002;59:269-77.
10 Köster M, Alfredsson L, Michelsen H, et al. Retrospective versus original information on physical and psychosocial exposure at work. Scand J Work Environ Health 1999;25:410-14.

11 Spielholz P, Silverstein B, Morgan M, et al. Comparison of self-report, video observation and direct measurement methods for upper extremity musculoskeletal disorder physical risk factors. Ergonomics 2001;44:588-613.

12 Viikari-Juntura E, Rauas S, Martikainen R, et al. Validity of self-reported physical work load in epidemiologic studies on musculoskeletal disorders. Scand J Work Environ Health 1996;22:251-9.

13 Alcouffe J, Manillier P, Brehier M, et al. Analysis by sex of low back pain among workers from small companies in the Paris area: severity and occupational consequences. Occup Environ Med 1999;56:696-701.

14 Balogh I, Orbaek P, Winkel J, et al. Questionnaire-based mechanical exposure indices for large population studies - reliability, internal consistency and predictive validity. Scand J Work Environ Health 2002;27:41-8.

15 Devereux JJ, Buckle PW, Vlachonikolis IG. Interactions between physical and psychosocial risk factors at work increase the risk of back disorders: an epidemiological approach. Occup Environ Med 1999;56:343-53.

16 Halpern $M$, Hiebert $R$, Nordin $M$, et al. The test-retest reliability of a new occupational risk factor questionnaire for outcome studies of low back pain. Appl Ergon 2001;32:39-46.

17 Hollmann S, Klimmer F, Schmidt KH, et al. Validation of a questionnaire for assessing physical work load. Scand J Work Environ Health 1999;25:105-14.

18 Pope DP, Silman AJ, Cherry NM, et al. Validity of a self-completed questionnaire measuring the physical demands of work. Scand J Work Environ Health 1998;24:376-85. 
19 Wilktorin C, Vingard E, Mortimer M, et al. Interview versus questionnaire for assessing physical loads in the population-based MUSIC-Norrtälie study. Am J Ind Med 1999:35:441-55.

20 Wiktorin C, Karlqvist L, Winkel J. Validity of self-reported exposures to work postures and manual materials handling. Stockholm MUSIC I Study Group. Scand J Work Environ Health 1993;19:208-14.

21 Waters TR, Putz-Anderson V, Garg A, et al. Revised NIOSH equation for the design and evaluation of manual lifting tasks. Ergonomics 1993;36: 749-76

22 Genaidy A, Beltran J, Yeung S, et al. Use of human expertise in the evaluation of manual lifting activities. Occup Ergon 2000;2:105-24.

23 Yeung SS, Genaidy AM, Deddens J, et al. Prevalence of musculoskeletal symptoms in single and multiple body regions among manual handling workers in Hong Kong and effects of perceived risk of liffing injury on musculoskeletal symptoms. Spine 2002;27:2166-72.

24 Yeung SS, Genaidy AM, Deddens J, et al. What is a demanding lifting job for manual handling workers in Hong Kong? Ergonomics 2003:46:574-97.

25 Yeung SS, Genaidy AM, Karwowski W, et al. Reliability and validity of selfreported assessment of exposure and outcome variables for manual lifting tasks: a preliminary investigation. Appl Ergon 2002;33:463-9.

26 Kuorinka L, Johnsson B, Kilbom A, et al. Standardised Nordic questionnaires for the analysis of musculoskeletal symptoms. Appl Ergon 1987;18: 233-7. 27 SAS/STAT. User's Guide: Statistics. Version 8. Cary, NC: SAS Institute,
28 Kilbom A. Assessment of physical exposure in relation to work-related musculoskeletal disorders - what information can be obtained from systematic observations? Scand J Work Environ Health 1994:20:30-45.

29 Burdorf A, Rossignol M, Fathallah FA, et al. Challenges in assessing risk factors in epidemiologic studies on back disorders. Am J Ind Med 1997;32:142-52

30 Burdorf A, van der Beek A. Exposure assessment strategies for work-related risk factors for musculoskeletal disorders. Scand J Work Environ Health 1999;25(suppl 4):25-30.

31 Davis KG Heaney CA. The relationship between psychosocial work characteristics and low back pain: underlying methodological issues. Clinical Biomechanics 2000; 15:389-406.

32 Hoogendoorn WE, van Poppel MN, Bongers PM, et al. Systematic review of psychosocial factors at work and private life as risk factors for back pain. Spine 2000;25:2114-25.

33 Waters TR, Putz-Anderson V Garg A. Applications manual for the revised NIOSH Liffing Equation. Publication no. 94-110. Cincinnati, OH: DHHS (NIOSH), 1994

34 Yeung SS, Genaidy AM, Huston RL, et al. Assessment of manual lifting activities using worker expertise: a comparison of two worker populations. Asian Journal of Ergonomics 2001;1:11-23.

35 Yeung S, Genaidy A, Huston R, et al. An expert cognitive approach to evaluate physical effort and injury risk in manual liffing-a brief report of a pilot study. Human Factors and Ergonomics in Manufacturing $2002 \cdot 12: 227-34$

Link to Medline from the homepage and get straight into the National Library of Medicine's premier bibliographic database. Medline allows you to search across 9 million records of bibliographic citations and author abstracts from approximately 3,900 current biomedical journals. 